\title{
eCAD System Design - Applications in Architecture
}

\author{
A.D. Styliadis, D.G. Konstantinidou, K.A. Tyxola
}

\begin{abstract}
The rapid advances in learning technologies, computer modeling, multimedia and spatial sciences, as well as the availability of many powerful graphics PCs and workstations, make 3-D modeling-based methods for personalized e-learning with eCAD (modeling) functionality feasible. Personalized eCAD learning is a new term in engineering, environment and architecture education, related to the development of learning educational units (3-D learning objects) with re-usable digital architecture functionality, and introduced to literature for the first time within this paper. In particular, for university education courses in eCAD, digital architecture, design computing and CAAD (reagarding spatial information systems, architectures, monuments, cultural heritage sites, etc.), such a e-learning methodolgy must be able to derive spatial, pictorial, geometric, spatial, topological, learning and semantic information from the target object (a 3-D model) or scene (a 3-D landscape environment) or procedure (a 3-D simulation approach to a phenomenon), in such a way that it can be directly used for e-learning purposes regarding the spatial topology, the history, the architecture, the structure and the temporal (time-based) 3-D geometry of the projected object, scene or procedure. This paper is about the system design of such a e-learning method. For this purpose, the requirements, objectives and pedagogical extensions are presented and discussed. Finaly, a practical project is used to demonstrate the functionality and the performance of the proposed methodology in architecture.
\end{abstract}

Keywords: e-learning documentation, modeling functionality, digital photography, CAD, historical living systems

\section{Introduction}

The rapid advances in digital imaging sensors and scanners, off-the-shelf haptic devices, computer modeling software and the availability of many powerful graphics PCs and workstations make a method for personalized eCAD learning with 3-D modeling or 2-D drafting functionality feasible (Kalay, 2006). Personalized eCAD learning is a new term in informatics, engineering and architecture, related to digital architecture documentation with e-learning functionality, and introduced to literature for the first time within this paper.

The proposed term personalized eCAD learning is defined as a digital architecture documentation procedure with e-learning functionality based on metric and non-metric (qualitative) data, and spatial and 3-D modeling semantic information (please see next Section).

In particular, for the historical living systems (i.e. monuments, churches, basilicas, archaeological sites, etc.), such a methodolgy must be able to derive pictorial, geometric, spatial, topological, learning and semantic information from the target architectural object (historical living system), in such a way that it can be directly used for e-learning purposes regarding the history, the architecture, the structure and the temporal (time-based) 3-D geometry of the projected historical living system.

Improvements and new developments in the fields of sensor technology and computer modeling allow the acquisition of digital images in video-realtime, without developing and digitizing a photographic film (Streilein, 1996; Kazakeviciute et al., 2005).

Such a system -which is well described by Andre Streilein from the ETH Zurich- for digital photogrammetry and architectural design consists of two sub-systems: a sub-system for the digital photogrammetric station and a sub-system for the CAAD (Streilein, 1996; Streilein et al., 1992). In this do- 
main the aim of a method for e-learning documentation is to make the photogrammetric data acquisition and processing easier and faster, to create a three-dimensional geometric and semantic object description, and to allow CAAD/multimedia data integration, haptic rendering, ísualization and architectural processing in an easy and user-friendly way (Vladoiu, 2004; Weber, 2004).

Therefore, such a method must be capable to acquire imagery with sufficient resolution, process the data with a big leíel of automation, and pass the results to a data structure useful for 3-D CAAD modeling (Hirschberg et al., 1996). This can be achieved using solid-state sensors and manual, semiautomatic or automatic measurement techniques. Also, for environmental management purposes, the current status of a relative methodology for such a system is described by L. Dimen et al. (2005) and a relative method is being deíeloped in a joint project of the ATEI of Thessaloniki in co-operation with the AGORA University of Oradea, Romania.

With the constant progress of multimedia technology and network bandwidth, the traditional teaching environment that based on text and pictures, will be integrated with media streams, 3-D modeling, intelligent agents, mathematics, virtual reality, haptic rendering and spatial objects (scienses)ů as described by A. Styliadis et al. (2006) for the GIS case, by Engeli et al. (1996) for the intelligent agents, by I. Dzitac (2000, 2002) and by I. Dzitac et al. (2007) for the mathematics case, and by Silva et al. (2002) for the insertion of 3-D architectural objects in photography. For this reason, in this paper, the proposed methodology shows and demonstrates an architecture (3-D model) that can support these new, rich in e-learning functionality, environments.

Recently, more and more systems come up that use any CAAD and semantic information available prior the measurement process. Such a system is the modelling-and-rendering system developed at the University at Berkeley by Debevec et al. in 1996. This system uses a rough object description in order to guide a stereo matching technique for the digital reconstruction of the primary object details with relative accuracy better than 10-3.

Another similar system (a CAAD system named "NAOS"), dealing with 3-D geometry (with relative 10-3 accuracy as well) and qualitative information for CAAD documentation, was developed in 1997 at the Aristotle University of Thessaloniki, School of Surveying Engineering and at the ATEI of Thessaloniki, Greece (Styliadis, 1997).

Also, very interested is the work at the University of Helsinki from H. Haggren and S. Mattila (1997) dealing for 3-D indoor modeling development based on videography data. In particular, in this work a functional 3-D model of indoor scenes is built first and the measurements of the geometry based on video images are performed thereafter.

Finally, an interested CAAD system under development exists at the University of Delft (Frank van den Heuvel, 2003), which makes use of a priori geometric object information in the form of parameterized object models with image lines as the main type of observations.

On the other hand, e-learning is a process that needs quite amount of mental and body strength. In order to promote the e-learning efficiency, it is important to improve the learning environment and this is the case of the proposed methodology (e-learning with CAAD functionality).

Apart from traditional design, the media stream or the virtual reality, can stimulate learner even more, reinforce the learner's motivation, attention and mentality. Some systems adopt different technology and implemented similar environment also demonstrate satisfactory results. However, they need to spend a lot of money and time to achieve that, such as VRML (Virtual Reality Modeling Language) it can establishes a virtual 3-D scene with walk-through functionality in the scene by a simple parameter, but while controlling the behaviors of the 3-D objects that enhance photorealism -such as the materials, the lights, the object scale, etc. - a script procedure must be writen in the complicated VRML markup language. Evenmore, the VRML modeling relative inaccuracy is greater than 10-3 and so, this is not acceptable for e-learning documentation applications.

The proposed method is based on a virtual learning environmental architecture that integrates synchronous, asynchronous and co-operative characteristics. 
The paper is structured as follows: In Section 2 (Personalized eCAD Learning: Term Formulation) the new term Personalized e-learning is introduced and described. In Section 3 (Personalized eCAD Learning: The System Design - Learning Requirements) an overview of the proposed personalized e-learning methodology is given. The Section 4 (Personalized eCAD Learning: The Main Streams) presents the main sub-systems outline design of the proposed e-learning methodology. Finaly, in Section 5 (Personalized eCAD Learning: An Application in Architecture) a practical 3-D model based application is presented and its e-learning functionality is discussed.

\section{Personalized eCAD Learning: Term Formulation}

Personalized eCAD learning is a new term in engineering and digital architecture, related to digital (geometric- and semantic-based) learning with re-usable spatial functionality, and introduced to literature for the first time within this paper.

The proposed term personalized eCAD learning is defined as a digital documentation procedure with e-learning re-usable spatial functionality based on metric and non-metric (qualitative) data, and spatial 3-D modeling semantic information. At the 'heart' of this e-learning is the 3-D model (vector format) of the object (which could be any architecture, building, monument, etc.) or the process (environmental polution, weather forecast, water flood estimation, etc.) being described (Dimen, 2005).

The objectives of the personalized eCAD learning are:

- to facilitate and encourage the collaboration and the critical awareness between the design students, scientists and professionals (architects, designers, engineers and so on).

- to design virtual spaces using different representation methods and techniques for haptic rendering regarding architectures, landscapes and urban design.

- to communicate through 3-D model-based multimedia data in ways traditional CAAD, photography and video does not support.

- to support access to prior understandings regarding the 'pathology' (nature) and the characteristics of the described object or process.

- to allow ideas exchange and to support design autonomy.

- to test the efficiency of the various sub-systems involved in design and construction processes for the Architecture, Engineering and Construction (AEC) community.

- to promote self-directed reusable learning exercises which lead to a critical awareness of the learning process and the learner's empirical background.

Similarly, the pedagogical profits are:

- the establishment, through this documentation, of a new reality in education and design practice, whereby the accepted realism and the level of the 3-D modeling accuracy (or inaccuracy), of the object or the process, are not so necessary to communicate performative and reusable educational and design concepts (Martin et al., 2004).

- the real-time collaborative and reusable interactivity.

- the feedback (learning domain 3-D ontologies for semantic CAAD descriptions).

- the ability to develop manual, semi-automatic or automatic reusable CAAD learning tools that could support architectural, photogrammetric, art, historical or archaeological training and education. 
The pedagogical strategy of the personalized eCAD learning is based on encouraging and facilitating the communication and ideas exchange between the personnel involved in the design, implementation and spatial analysis process. Finaly, active role, interaction, group work and design autonomy are the characteristics of the proposed personalized eCAD learning.

\section{Personalized eCAD Learning: The System Design - Learning Require- ments}

The structure and the processing steps for the proposed personalized eCAD learning method are shown in Fig. 1. In this figure, the relation among the 3-D learning objects with modeling functionality and the available learners' (engineers, CAD personnel, architects) profiles are presented in connection with the geometric, topologic and thematic spatial data.

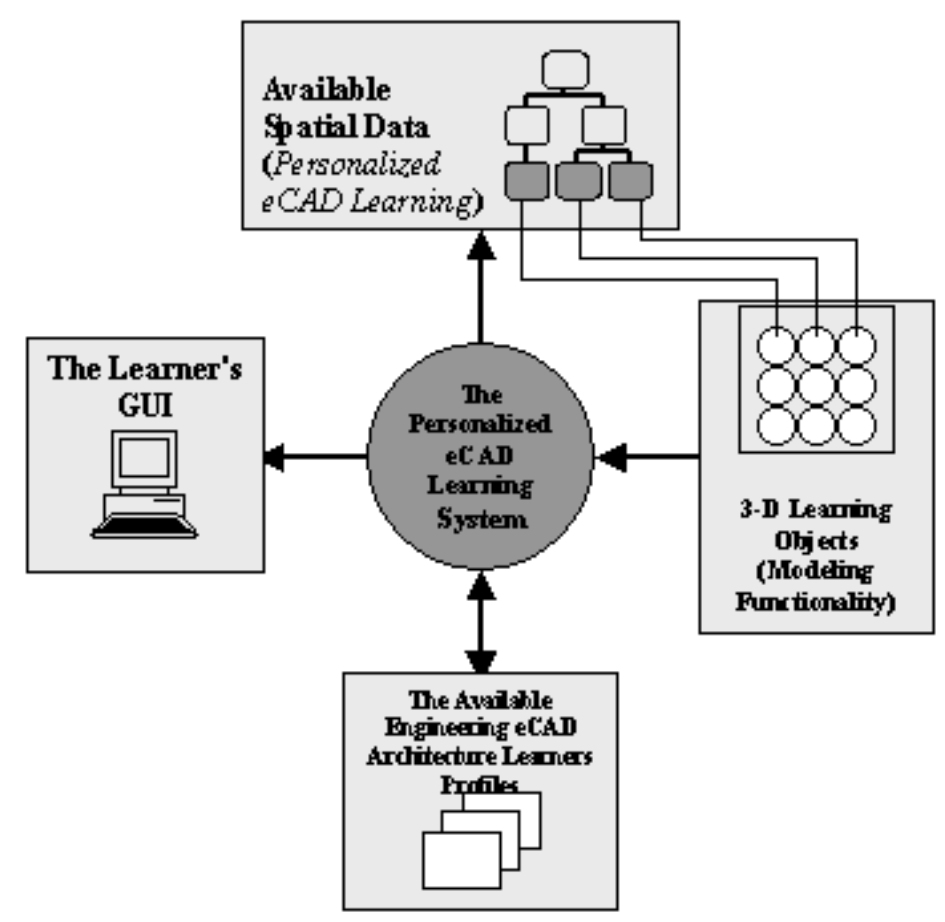

Figure 1: The Proposed eCAD System Design (Personalized eCAD Learning)

On designing the proposed methodology for the e-learning documentation, the statistical analysis results from an e-learning course in CAAD and the VRlab research project at the ATEI of Thessaloniki are examined (Tsakiris et al., 2005). So, according to students suggestion, the functional specifications for a 3-D based e-learning system are defined as follows:

- 3-D map video processing

- 2-D image processing

- Archive or historical photography, rich in geometric regularities and properties (i.e. clues, like: planarity, parallelism, orthogonality, symmetry, perpendicularity, topology, etc.), processing (Styliadis et al., 2003)

- Item-by-item 3-D modeling functionality in an e-learning CAAD environment 
- Haptic rendering of the resulting virtual representations of both the 3-D maps (models) and 2-D images (drawings)

- GUI with drag-n-drop functionality

- Multimedia functionality

- Learning functionality incorporating historical and semantic data

- Force-field haptic rendering functionality

- Virtual Reality functionality

- Noting- and shared-board functionality

- Non-stop study functionality

Actually, what the learner needs is a synchronism and adaptive e-learning system which can interact in real-time with the teacher in class $(\mathrm{Wu}, 2002)$. In this domain an asynchronous system can let learner to study in his free time by adapting learning object selection (based on discrete and reusable 3-D modeling items) in intelligent learning systems (Karampiperis et al., 2004). Also, such as system can let learners discuss with each other through media stream. Besides, they also need 3-D virtual environment with haptic rendering functionality, which can increase learner's interest and attention.

\section{Personalized eCAD Learning: The Main Streams}

After defining its functional specifications the main sub-systems (streams) of the re-usable e-learning system are defined as follows:

- Media Stream Services: This is the server sub-system; for which a number of media stream servers are needed (e.g. a system or central server). These servers can provide data (photography, imagery, history, architecture, modeling) for learners on real-time. These servers can also store material in repository (i.e. material palettes) which then can be searched by researchers or learners (e.g. students in architecture, art, history, etc.).

- Virtual Learning Environment for 3-D Visualization: This is the client sub-system; which includes a user interface based on 3-D graphics, haptic equipment and virtual reality tools (Petrovic, 1996). It is the stage for the learner and it includes virtual and resource classroom, chat room, etc. This e-learning sub-system provides chatting functionality on a learner-to-learner or learner-to-teacher basis. After the learner's logon to the system, he can control the learning process on focusing: (i) on particular 3-D modeling and rendering methods supporting e-learning functionality, e.g. haptic rendering, phong shading rendering (Fig. 2) or phong rendering; and (ii) on particular details of the historical living system using a GUI input device like the keyboard, the light-pen or the mouse. Evenmore, using this stream the learner can also communicate on-line with other learners (e-students).

- Web Portal: This e-learning stream provides the learner with additional information and operates as an integration platform for the entire e-learning documentation. This stream mainly includes the system's operation manual, monument's relevant documents and teaching materials, monument's architecture, history, archive (historic) photography, digital imagery, etc. 


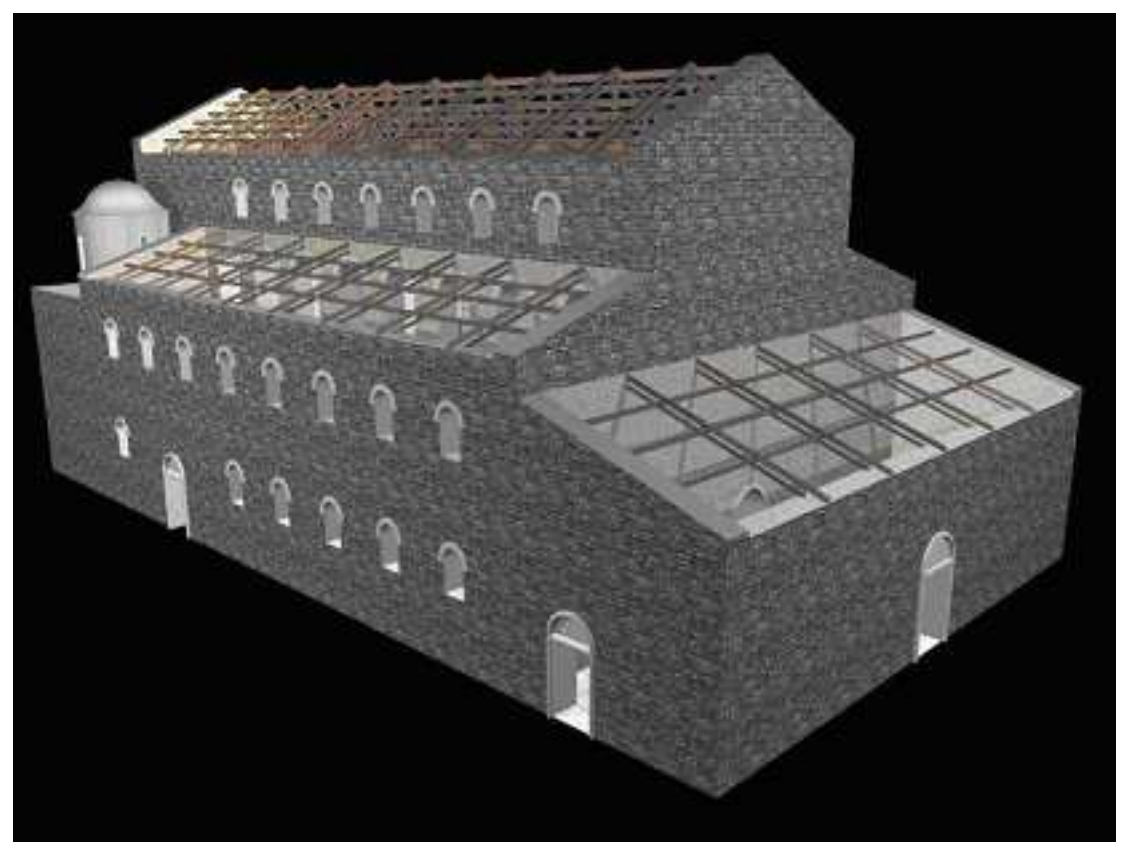

Figure 2: 3-D modeling of Aghios Achilleios basilica

\section{Personalized eCAD Learning: An Application in Architecture}

Beyond the thirsty coasts of Greece lies a lush heartland where a coachload of sunburnt tourists are a rarer sight than a flock of pink-backed pelicans. This is Macedonia, a land of legendary battles and untamed landscapes, more familiar for the news headlines it attracts than for its startling natural beauty.

Nestled, among Macedonia's verdant mountains, are the twin cool lakes of Prespa (North-West Greece). Declared as a National Park in 1974; these twin lakes provide a sanctuary for over 280 species of birds and the largest pelican breeding ground in the world. Though stranded on the edge of Greece, Prespa lies at the 'heart' of the Balkans. Straddling Greece, Albania and the Former Yugoslavian Republic of Macedonia (FYROM), these lakes are a smooth expanse of serenity caught in the crossfire of shifting borders. Locals are an unusual stew of immigrants and refugees from Pondos and Asia Minor, and nomadic Vlachs; many still speak their native dialects. But as with most of rural Greece, Prespa's population is dwindling.

At the turn of the century, there were 12,000 inhabitants and 21 villages. Now, only 1,200 locals and 12 villages are left; they survive now, as then, by fishing and farming. Until 1969, locals carried special ID cards and foreign visitors required a visa. Even today, tourism is just a slow trickle in this watery wonderland.

The Aghios Achilleios basilica, in lakes Prespes, was chosen to demonstrate the functionality and efficiency of the proposed method. Actually, the Aghios Achilleios basilica is located at the Aghios Achilleios island on the minor Prespes lake.

The monument is a three-aisled, wooden-roofed basilica with a narthex and domes over the parabemata (Fig. 3). It was founded in ca. 986-990 by tsar Samuel of Bulgaria. Initially, it was the cathedral of Samuel's short lived empire and later, until the middle of the 15th century, was an episcopal church.

A tomb covered with a relief tombstone is preserved in the south arm of the cruciform diaconicon; tradition say that the relics of Aghios Achilleios were kept in this tomb. Along the south wall of the south aisle, four other graves are preserved, in which important persons of the church or the local community were buried.

The few fragments of the wall paintings belong to two different layers and have been removed from 


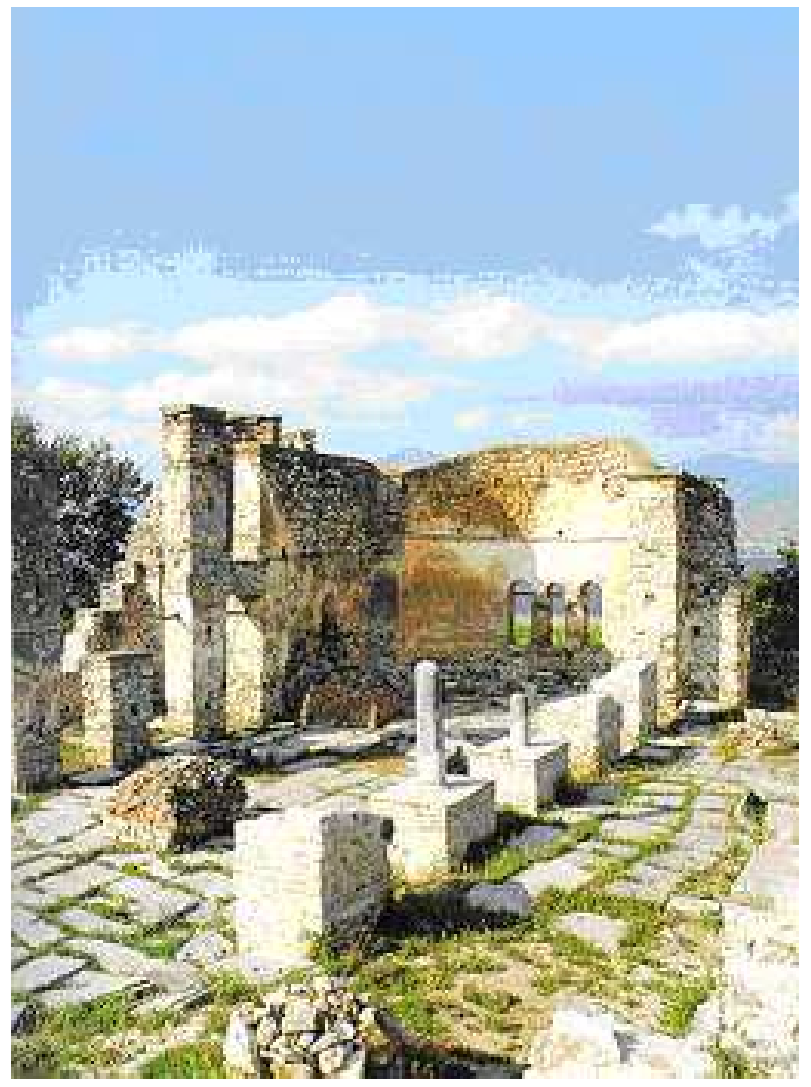

Figure 3: The Aghios Achilleios basilica at the twin lakes Prespes

the building. They are now on display in the exhibition of Byzantine and post-Byzantine art, in the Byzantine Museum of Florina. Today, only a part of the super-structure of the building is preserved, especially on the east side.

It stands to a privileged and dominating position, nearly 20 metres above the lake of Prespes at the isle of Aghios Achilleios. The monument is about $22 \mathrm{~m}$ in length, $16 \mathrm{~m}$ in width and $6 \mathrm{~m}$ in height. A detailed discussion about the history, architectural design and construction of this basilica is given by Prof. Emeritus of Architecture Nikolaos Moutsopoulos (1999). The monument has been under restoration since 1987, and the wall masonry will be rebuilt as long as there is available evidence of its construction.

The result of the photogrammetric processing was a 3-D geometric and semantic object description, which was passed automatically via Java-MDL programming (Java and C++ coding) to the MicroStation Masterpiece CAAD system. This system is able to pre-process the data and store it in data structures adapted to architectural purposes; allowing, as well, data transformation into other representations in an easy way.

For the personalized eCAD learning, the task of the learner is the creative finding of new modeling solutions (point or parallel perspective) as well as to evaluate the current modeling accuracy, for both the point and the parallel perspective projections, in connection with the imagery processing equipment and technique used. More for 3-D reconstruction from perspective images could be found in (Yang et al., 2005).

The e-learning documentation is important for documentation and visualization purposes, and for complex simulations, manipulations and analysis of the target architectural object. This could be used in e-learning courses about architecture, archaeology and art history, in preservation of historical monuments and sites, in regional and local planning, as well as in renovations, reconstructions and reverse engineering projects. 


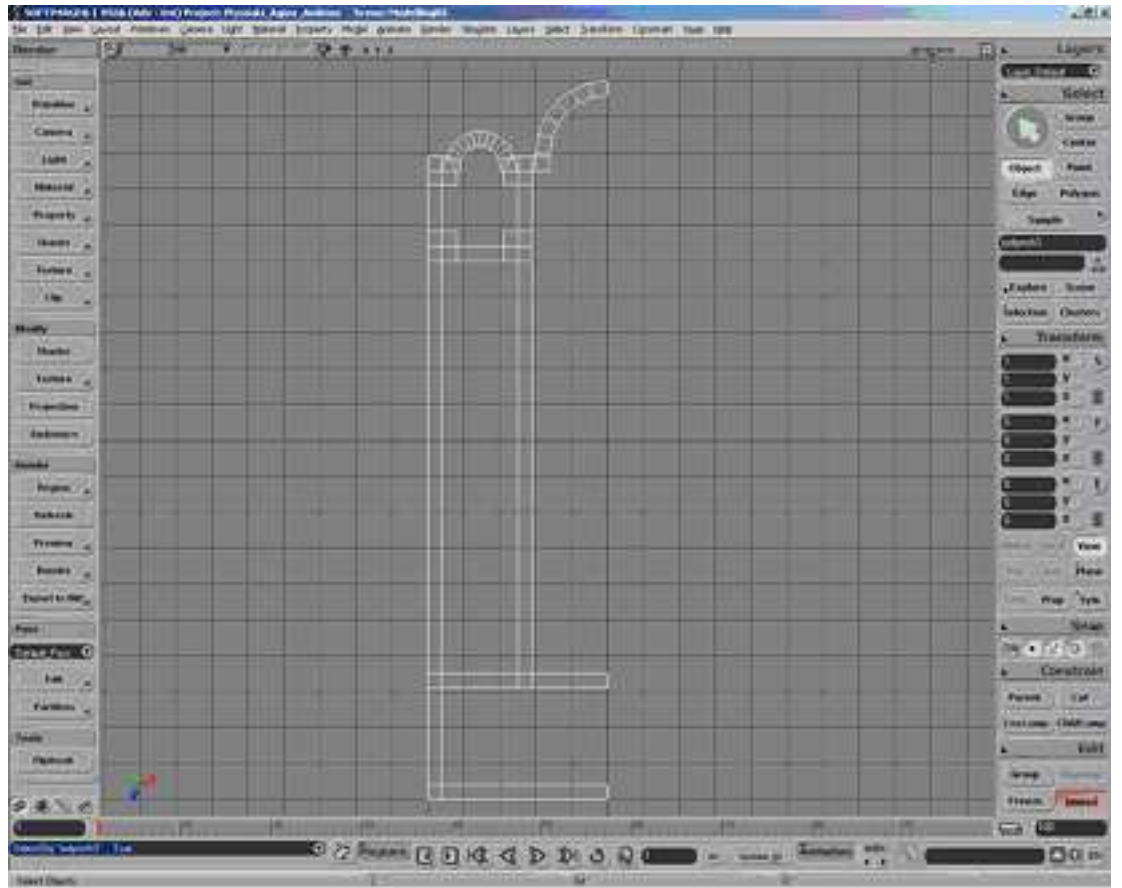

Figure 4: A top view of the east part of Aghios Achilleios basilica (architectural drawing)

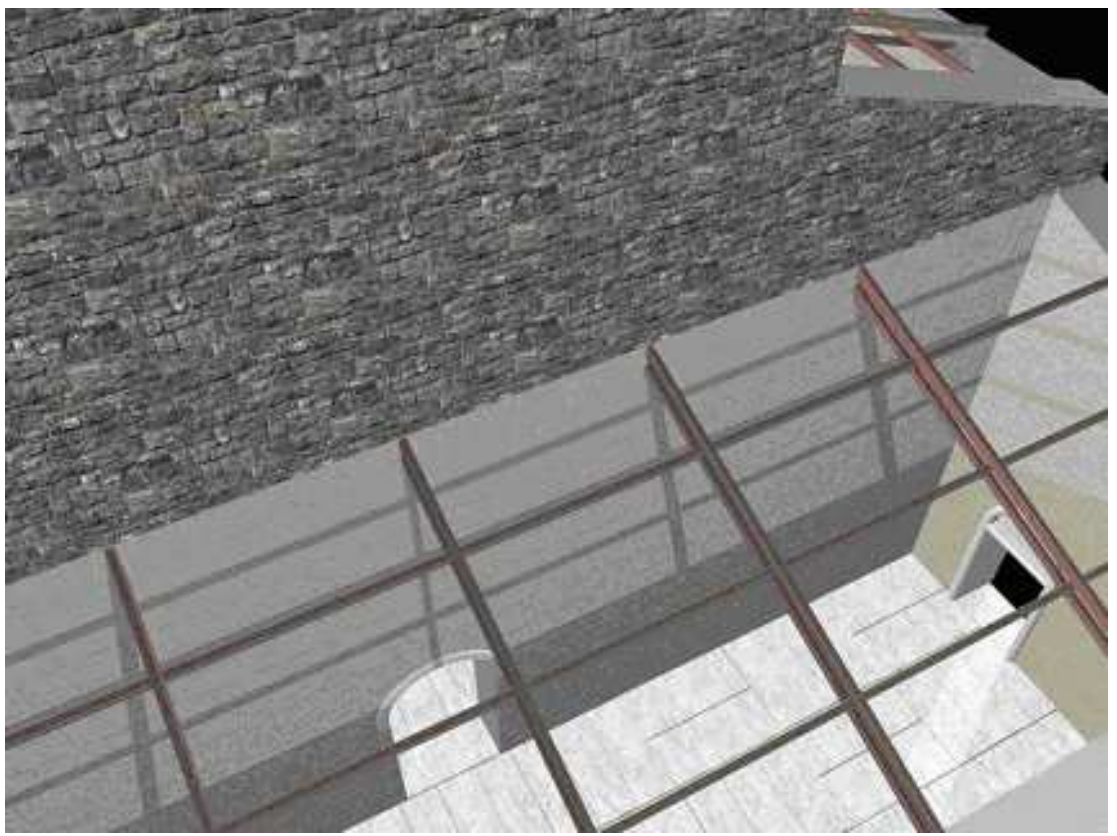

Figure 5: Phong haptic rendering: A point-perspective view of the Aghios Achilleios basilica CAAD Model (haptic representation based on digital low-resolution Canon CI-10 imagery) 


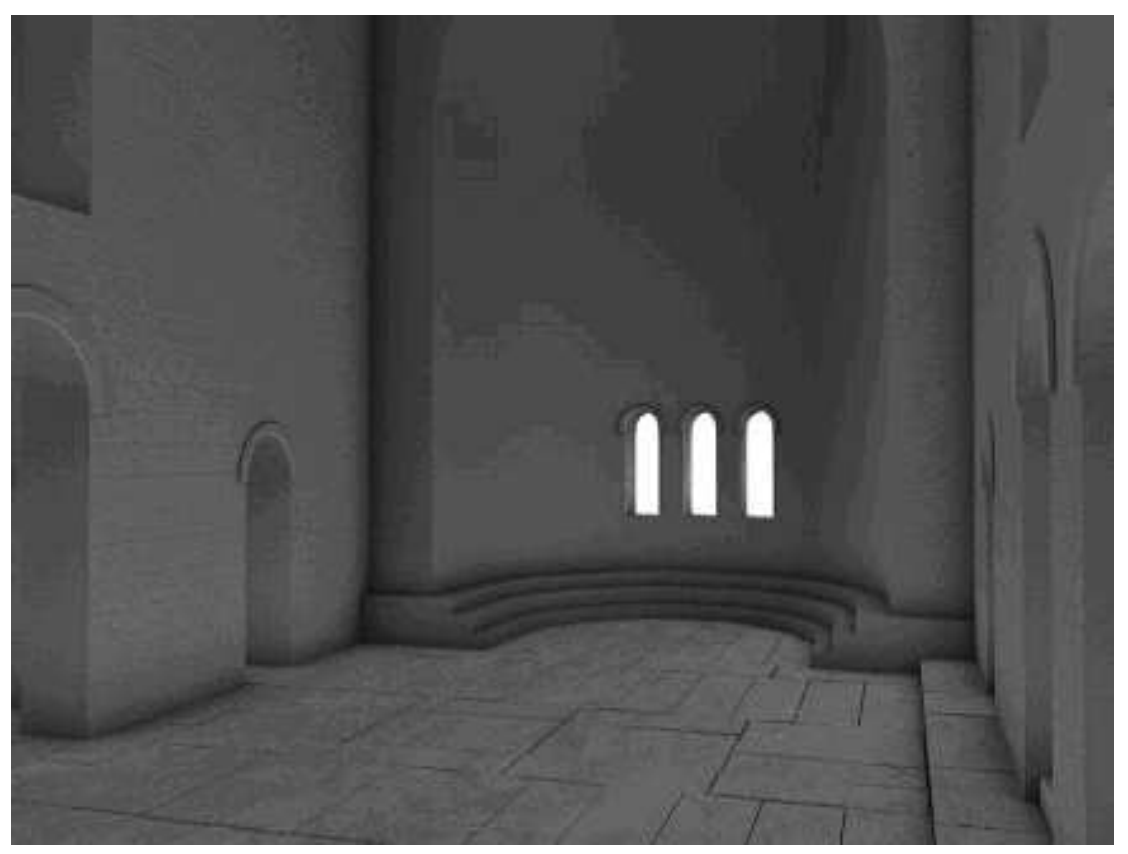

Figure 6: Phong haptic rendering: A parallel-perspective view of the Aghios Achilleios basilica CAAD Model (haptic representation based on digital low-resolution Canon CI-10 imagery)

Figure 4 shows the top view of an architectural drawing regarding the east part of the Aghios Achilleios basilica, and Figures 5 and 6 illustrate two haptic rendering perspective views if the photogrammetric generated CAAD model of the same monument. It is important to note that haptic interaction and rendering is especially important to e-learning students and populations with disabilities, such as the visually impaired, because tactile interpretation is one of the most important modalities they can use to perceive the world and to appreciate the monuments and the cultural heritage.

\section{Acknowledgments}

The current paper is supported by the EPEAEK II - Archimedes research project "Personalized Learning in a Reusable Way" of the Alexander Institute of Technology \& Education (ATEI), Department of Information Technology, Thessaloniki, Greece. The EPEAEK project is co-financed by the European Union (75\%) and the Greek Ministry for Education \& Religious Affairs (25\%).

\section{Bibliography}

[1] P. Debevec, C. J. Taylor and J. Malik, "Modeling and Rendering Architecture from Photographs: A Hybrid Geometry- and Image-based Approach", Proceedings of SIGGRAPH 1996, pp. 11-21, 1996.

[2] L. Dimen and I. Ienciu, "Environmental Management Plan", RevCAD Journal of Geodesy and Cadastre, Vol. 5, pp. 271-274, 2005.

[3] I. Dzitac, "Random-filtred asynchronous iterative method", Bul.St. Univ.Baia Mare, Seria B, Mat. Inf., Vol. XVIN r.1, pp. 17-24, 2000.

[4] I. Dzitac, Parallel and distributed procedures in solving of some operator equations / Procedee de calcul paralel si distribuit in rezolvarea unor ecuatii operatoriale, Ph.D. Thesis, Univ. "Babes-Bolyai" din Cluj-Napoca, 230 pg., 2002 (in Romanian). 
[5] I. Dzitac, S. Dzitac, E. Valeanu, "Web Distributed Computing for Landscape Architecture", in N. Eleftheriadis, A. Styliadis, I. Paliokas (eds), Proceedings of the International Conference "Landscape Architecture and New Technologies" - LANT07, 25-26 May 2007, Drama, Greece, ISBN 978-960-363-027-2, pp. 25-36, 2007.

[6] M. Engeli and D. Kurmann, "Spatial objects and intelligent agents in a virtual environment", Automation in Construction, Vol. 5, pp. 141-150, 1996.

[7] H. Haggren and S. Mattila, "3-D Indoor Modeling from Videography", In Proceedings of SPIE, Vol. 3174 (Videometrics V), pp. 14-20, 1997.

[8] F. van den Heuvel, Automation in Architectural Photogrammetry (Line-Photogrammetry for the Reconstruction from Single and Multiple Images), Ph.D. Thesis, NCG and the Royal Netherlands Academy of Arts and Sciences (KNAW) (Eds.), ISBN: 9061322812, 2003, The Netherlands.

[9] U. Hirschberg and A. Streilein, "CAAD meets digital photogrammetry: modelling 'weak forms' for computer measurement", Automation in Construction, Vol. 5, pp. 171-183, 1996.

[10] Y. E. Kalay, "The impact of information technology on design methods, products and practices", Design Studies, Vol. 27, pp. 357-380, 2006.

[11] P. Karampiperis and D. Sampson, "Adaptive learning object selection in intelligent learning systems", Journal of Interactive Learning Research, Vol. 15, No. 4, 2004.

[12] G. Kazakeviciute, E. Januskevicius, R. Rosenbaum and H. Schumann, "Tamper-proof Image Watermarking, based on existing public key infrastructure", Informatica, Vol. 16, No. 1, pp. 75-92, 2005.

[13] Pedro Leao Ramos Ferreira Neto and Margarida Amaral, "CAAD and e-Learning: a Blended Approach", eLearning Papers, Vol. 3, ISSN: 1887-1542, 2007.

[14] D. Martin and I. Sommerville, "Patterns of cooperative interaction: ethnomethodology and design", ACM Transactions on Computer-Human Interaction, Vol. 11, No. 1, pp. 59-89, 2004.

[15] N. K. Moutsopoulos, The Basilica of St. Achilleios in lake Prespes, Paratiritis Editions, ISBN: 960-260-9931, 1999, Thessaloniki (in Greek).

[16] I. K. Petrovic, "Computer design agents and creative interfaces", Automation in Construction, Vol. 5, pp. 151-159, 1996.

[17] B. Silva, V. Alvarez, P. Cezar, P. Carvalho and M. Gattass, "Insertion of three-dimensional Objects in Architectural Photos", Journal of WSCG, Vol. 10, No. 1, 2002.

[18] A. Streilein, "Utilization of CAD models for the object oriented measurement of industrial and architectural objects", In International Archives of Photogrammetry and Remote Sensing, Vol. XXXI, Part B5, pp. 548-553, 1996.

[19] A. Streilein, H. Beyer and T. Kersten, "Digital photogrammetric techniques for architectural design", In International Archives of Photogrammetry and Remote Sensing, Vol. XXIX, Part B5, pp. 825-831, 1992.

[20] A. D. Styliadis, "Digital documentation of historical buildings with 3-d modeling functionality", Automation in Construction, Vol. 16, No. 4, pp. 498-510, 2007.

[21] A. D. Styliadis, I. D. Karamitsos and D. I. Zachariou, "Personalized e-Learning Implementation - The GIS case", International Journal of Computers, Communications \& Control, Vol. I, No. 1, pp. 59-67, 2006.

[22] A. D. Styliadis and M. Gr. Vassilakopoulos, "A spatio-temporal geometry-based model for digital documentation of historical living systems", Information \& Management, Vol. 42, pp. 349-359, 2005.

[23] A. D. Styliadis, P. G. Patias and N. X. Zestas, "3-D Computer Modeling with Intra-Component, Geometric, Quality and Topological Constraints", Informatica, Vol. 14, No. 3, pp. 375-392, 2003. 
[24] A. D. Styliadis, Digital Documentation of Monuments and Sites with 3-D Geometry and Qualitative Information. Ph.D. Thesis, Faculty of Rural \& Surveying Engineering, Aristotle University of Thessaloniki, 1997, Greece (in Greek).

[25] A. Tsakiris, I. Filippidis, N. Grammalidis, D. Tzovaras and M. G. Strintziz, "Remote experiment laboratories using virtual reality technologies: The VRlab project", Acta Universitatis Apulensis (Mathematics and Informatics), Vol. 11, pp. 365-378, 2005.

[26] M.-M. Vladoiu, "Towards building an open digital library for instructional design that facilitates reflective e-instruction", Informatics in Education, Vol. 3, No. 1, pp. 127-140, 2004.

[27] W. Weber, "SelMa - Self-guided Learning in Teaching Mathematics", Informatics in Education, Vol. 3, No. 1, pp. 141-150, 2004.

[28] Honggang Wu, Designing a Reusable and Adaptive e-Learning System, M.Sc. Thesis, University of Saskatchewan, Saskatoon, 2002.

[29] A. Y. Yang, K. H. Huang, S. Rao, W. Hong and Y. Ma, "Symmetry-based 3-D reconstruction from perspective images", Computer Vision and Image Understanding, Vol. 99, pp. 210-240, 2005.

Athanasios D. Styliadis, Debbie G. Konstantinidou, Kyriaki A. Tyxola The Alexander Institute of Technology and Education Department of Information Technology The Archimedes 2.2.17 Research Project P.O. Box 141, 57400 Thessaloniki,Greece E-mail: styliadis@ath.forthnet.gr

Received: December 20, 2007 